\title{
Sleep Habits and Excessive Daytime Sleepiness in a Population of Spanish Health Care Employees
}

\section{Meritxell Espuga', Maria Antonia Ramon PT', Alfons Ayora', Manuel Alonso', Gabriel Sampol', Guadalupe Silveira ${ }^{2}$ and Patricia Lloberes ${ }^{2 *}$}

\author{
${ }^{1}$ Unitat de Prevenció de Riscos Laborals, Spain \\ ${ }^{2} S e r v e i$ de Pneumologia, Hospital General Universitari Vall d'Hebron, Barcelona, Spain
}

*Corresponding author: Patricia Lloberes, Servei de Pneumologia, Hospital General Universitari Vall d'Hebron Barcelona, Spain, E-mail: plloberes@vhebron.net

\begin{abstract}
Background and objectives: The aim of the study is to assess the sleep habits and prevalence of excessive daytime sleepiness (EDS) in Spanish health care workers and the relationship between sleep habits, EDS, anthropometric measurements, work shift, sleep apnea risk, and work commute traffic accidents.

Patients and methods: We conducted a cross-sectional observational study on subjects undergoing an annual medical screening administered by the Occupational Risk Prevention Unit at a hospital in Spain, providing anthropometric data and self-completed questionnaires: Epworth Sleepiness Scale, sleep habits questionnaire, Berlin Questionnaire and self-reported "work commute" traffic accident. Logistic regression models were performed to analyze factors associated with EDS and work commute traffic accidents.

Results: Five hundred and one hospital employees were studied (79\% women), age 43.1 (11.9) yrs., 19.4\% reported working a night shift, $6.6 \%$ showed EDS and $43.9 \%$ slept less than 7 hours on work days. Only in women night shift and sleep debt were significantly associated with EDS, (OR 2.64, p = 0.034 and OR 1.29, $p=0.044$ respectively) and age and a night shift were significant predictors of body mass index (coefficient $0.12, p=0.001$ and 1.56, $p=0.003$, respectively) and abdominal circumference (coefficient $0.29 p=$ 0.001 and $3.95, p=0.003$ respectively). "Work commute" traffic accidents, reported by $10.8 \%$ of respondents, were associated with dozing off while driving.

Conclusions: Prevalence of EDS and insufficient sleep is consistent with what has been described in the general population in other countries. In women, EDS is associated with sleep debt and night shifts whereas night shifts and age are associated with overweight variables. Self-referred sleepiness while driving is a risk factor for traffic accidents on a work commute.
\end{abstract}

\section{Keywords}

Excessive daytime sleepiness, Epworth sleepiness scale, work shift, Berlin questionnaire, Work commute traffic accidents

\section{Introduction}

Sleep disorders and sleep deficiency are a major health problem of great significant socioeconomic impact and adverse health effects. Over the last few decades there has been growing evidence to suggest that too little sleep and too much sleep are associated with adverse health outcomes, including total mortality, cardiovascular disease, diabetes, hypertension and respiratory disorders, obesity in both children and adults, and poor self-rated health [1]. Sleepiness relates to traffic accidents and sleep deprivation can impair neurobehavioral performance by an amount that is equivalent to a blood-alcohol concentration of $0.10 \%$ [2].

Studies targeting the general population have shown a highly variable prevalence of excessive daytime sleepiness (EDS), ranging from 0.5 to $35.8 \%$ [1,3-7]. EDS is associated with neuropsychological deficits that increase the probability of accidents and reduce work performance. EDS is the result of several possible causes such as behaviorally-induced insufficient sleep syndrome or narcolepsy, due to a medical condition or unspecified as listed in the International Classification of Sleep Disorders (ICSD-2) [8]. It is often multifactorial and frequently subjectively defined.

Sleepiness associated with insufficient sleep can be found in 1-4\% of the population [7]. Subjects reporting poor sleep quality and those sleeping less than 6 hours per night show an increased risk of traffic accidents [9]. Current research indicates a direct relationship between sleep deprivation and health risks, paid for by health insurance, workers' compensation insurance, and resulting in absenteeism and presenteeism [10].

Shift work, and in particular night work, can also result in subjective and objective sleepiness. Night shift workers who are used to sleeping fewer hours must work at the nadir of the circadian pattern, which promotes sleep, while their daytime sleep is truncated [11]. Night work is characterized by increased subjective and objective sleepiness. The effects are particularly severe in the early morning, often involving incidents of involuntary sleep [9]. Different studies suggest that a night shift is associated with higher risk of brief sleep episodes while driving and suffering "work commute" traffic accidents [12].

Obstructive sleep apnea (OSA) is another frequent cause of EDS, affecting $2-4 \%$ of the adult population. OSA patients are at an increased risk of sustaining traffic accidents.

Citation: Espuga M, Maria ARPT, Ayora A, Alonso M, Sampol G, et al. (2016) Sleep Habits and Excessive Daytime Sleepiness in a Population of Spanish Health Care Employees. J Sleep 
The prevalence of daytime sleepiness and insufficient sleep in health care workers has been hardly investigated as compared to its prevalence in the general population [13-15] and in working populations [16].

The identification of an association between EDS and medical errors in nurses brings to light the importance of assessing EDS in health employees. In addition, work commute traffic accidents are a frequent cause of work accidents [17] and drowsy-driving incidents can be related to work patterns and sleep restriction.

Given there is scarce information about EDS and sleep habits in Spanish health care employees, the aim of the present study is to assess the prevalence of subjective daytime sleepiness and to describe the sleep habits in a sample of subjects working at a hospital in Barcelona, Spain. We also wished to investigate the relationship between EDS, sleep schedules, anthropometric measurements, work shift, sleep apnea risk and "work commute" traffic accidents.

\section{Methods}

\section{Subjects}

From January to May 2009, a consecutive group of employees participating in annual medical screening at the Occupational Risk Prevention Unit of our hospital were invited to participate in the study. This Unit offers a physical examination to all employees, with an attendance rate of 1770 visits per year.

\section{Measurements}

Doctors of the Occupational Risk Prevention Unit asked participants to complete a health survey involving socio-demographic (age, sex) and occupational data (profession, job category and work shift), cigarette and alcohol consumption, a sleep habits' questionnaire, the Epworth Sleepiness Scale (ESS), [18] the Berlin Questionnaire; [19] subjects were asked if they ever had any "work commute" traffic accident. Employees at our hospital are assigned to a daytime shift (either from 8a.m to 3p.m or from 8a.m to 8p.m on alternate days) or a night shift (alternating 3 o 4 nights every other week). No data was collected about how long employees had been working a certain shift. The sleep habits questionnaire included information over the past month, on workday hours of sleep, normal sleep schedules, including bedtime routine and napping. Total sleep time was determined as the reported number of hours actually slept at night and during the day on both work days and non-work days. Self-reported sleep debt was calculated over a 24 hour period by subtracting the reported hours of sleep during work days from the reported hours of sleep on nonwork days. The use of sleep medication was recorded as never $(0$ per month), rarely (once per month), sometimes (2-4 per month), often (5-15 per month) or almost always (16-30 per month).

The ESS asks the individual to self-rate his or her average likelihood of dozing off (from 0 [no chance of dozing] to 3 [high chance of dozing]) during eight different routine activities (e.g., watching television or sitting and talking to someone). A total score greater than 10 indicates probable EDS. The Berlin Questionnaire itemizes responses within 3 categories related to sleep apnea. Subjects are classified as high risk or low risk based on their response to individual items and their overall score in the symptom category.

Somnolence while driving and "work commute" traffic accidents were identified based on affirmative responses to the questions "have you ever nodded off or fallen asleep while driving a vehicle" (consistent with the Berlin Questionnaire) and "have you ever had a traffic accident on your way to or from work," respectively.

The physician responsible for the medical screening collected the participant's anthropometric data (weight, height, body mass index (BMI) and abdominal circumference). Data collection was anonymous. The hospital's Ethics Committee approved the study and all subjects signed an informed consent.

\section{Data analysis}

A sample size of 429 subjects from a total number of 7000 hospital employees was needed to assess a prevalence of EDS of 5\%, based on an estimated prevalence of EDS of 5\% [2-7] and a precision of $2 \%$, using the software GRANMO 7.2 [20].

Data are presented as frequencies and percentages for qualitative variables, and as mean (SD) or median (IQR) for quantitative variables. Bivariate analyses were performed to: 1) ascertain the relationship between socio-demographic, anthropometric and lifestyle data, sleep habits and EDS, 2) identify factors associated with traffic accidents sustained while commuting to or from work and 3) identify factors associated with having dozed off while driving, using either unpaired t-test, Mann Whitney test, Chi-square, or Fischer's exact tests, as appropriate.

Logistic regression models were performed to analyze factors associated with: 1) daytime sleepiness, and 2) work commute traffic accidents. Variables were kept in the model if they were significantly associated in the bivariate analysis or if there was evidence on their association with the outcome in the literature and if they modified the estimates of the remaining variables ( $>10 \%$ change in regression coefficient). Further stratification analyses according to gender were conducted in order to study potential interactions. Analysis was conducted using Stata 12.1 (StataCorp, College Station, TX, USA). A $\mathrm{p}<0.05$ was considered significant.

Missing data resulted from non-completion of individual items on the health survey questionnaire. Ignoring missing data and conducting a complete case analysis may lead to serious bias in survey estimates and weakens a study. Customarily, nonresponse is compensated for through multiple imputation, which involves assigning a value for missing responses from the predictive distribution of each variable, thereby reducing bias in survey estimates. Given there were only a limited number of missing values on the responses to our questionnaires, and that our assessment is that these were either completely at random or at random, multiple imputation through chained equations was used to prevent data loss.

\section{Results}

Five hundred and one consecutive subjects were included in the study. Median ESS was 5 (3-7). EDS, according to ESS (ESS > 10), was found in 33 subjects $(6.6 \%$; $95 \%$ CI $4.4-8.8)$ and did not differ significantly by gender, $6.7 \%$ (95\% CI $1.8-11.5)$ in men and $6.6 \%$ (95\% CI 4.1-9.0) in women ( $\mathrm{p}=0.990)$. General characteristics of the participants and characteristics as they relate to the presence or not of EDS are shown in table 1.

Most were women $(79 \%), 11.6 \%$ were obese $\left(\mathrm{BMI}>30 \mathrm{Kg} / \mathrm{m}^{2}\right)$, $22.9 \%$ were active smokers, with a median cigarette consumption of 15 (13-21) packs/years, and $18.0 \%$ were daily alcohol consumers with a median of 15 (13-21) gr/day. No significant differences in BMI were identified between subjects with or without EDS.

$81.9 \%$ of subjects reported their professional activity as a health care provider (nurse, physical therapist, nursing assistant, and physician) and the remaining $18.1 \%$ were not health care providers (administrative worker, orderly, laboratory technician, researcher or other).

Night shifts were more prevalent in subjects with EDS than in employees not reporting EDS, although this difference was not statistically significant ( $33.2 \%$ vs. $18.4 \%, \mathrm{p}=0.054)$.

Sleep time during work days in the whole population was 6.8 (1.1) hours, with a sleep debt with respect to non-work days of 1 (0-2) hour. Sleep time on work days was less than 7 hours in $43.9 \%$ of the participants and less than 6 hours in $12.8 \%$. Sleep time schedules were regular in $72.3 \%$, and $25.3 \%$ habitually napped an average of 38 (3060 ) min. Most subjects referred never using sleep medication (82.0\%), whereas $3.4 \%$ and $1.8 \%$ referred using it almost always (16-30 days per month) or frequently (5-15 times per month), respectively. 
Table 1: Characteristics of 501 survey respondents.

\section{Socio-demographic and anthropometric data}

Age (years), mean (SD)

Female, $\mathrm{n}(\%)$

Health Care Employee, n (\%)

Professional Category, $\mathrm{n}(\%)$

Administrative Assistant

Orderly

Nurse/Physical Therapist

Physician

Nursing Assistant

Laboratory Technician

Researcher

Other

Work shift, $\mathrm{n}(\%)$

Day shift

Night shift

Body Mass Index $\left(\mathrm{kg} / \mathrm{m}^{2}\right)$, mean (SD)

Body Mass Index, n (\%)

$\geq 30 \mathrm{~kg} / \mathrm{m}^{2}$

Abdominal circumference (cm), mean (SD)

Male

Female

Lifestyle

Active smokers, $\mathrm{n}(\%)$

Daily alcohol consumers, $\mathrm{n}(\%)$

All $\quad$ Participants with EDS

$n=501 \quad n=33$

43.1 (11.9)

$n=33$

$396(79.0)$

44.1 (9.7)

27 (81.8)

$52(10.3)$

20 (4.0)

170 (33.9)

74 (14.8)

$106(21.2)$

$40(8.0)$

12 (2.4)

27 (5.4)

404 (80.6)

97 (19.4)

24.8 (4.2)

58 (11.6)

93.4 (10.6)

$83.8(10.9)$

115 (22.9)

90 (18.0)

\begin{tabular}{|c|c|}
\hline Participants without EDS & \\
\hline$n=468$ & p \\
\hline $43.0(11.4)$ & 0.690 \\
\hline $370(79.1)$ & 0.990 \\
\hline 379 (80.9) & 0.997 \\
\hline- & \\
\hline- & \\
\hline- & \\
\hline- & \\
\hline- & \\
\hline- & \\
\hline- & \\
\hline- & \\
\hline $382(81.6)$ & 0.054 \\
\hline $86(18.4)$ & \\
\hline $24.7(4.3)$ & 0.808 \\
\hline $56(12.0)$ & 0.319 \\
\hline $93.4(10.7)$ & 0.961 \\
\hline $83.3(11.1)$ & 0.795 \\
\hline $103(22.0)$ & 0.065 \\
\hline $86(18.4)$ & 0.358 \\
\hline
\end{tabular}

Abbreviations: SD: standard deviation; EDS: excessive daytime sleepiness

Table 2: Sleep habits, Berlin Questionnaire, and "work commute" traffic accidents according to EDS in 501 survey participants.

\begin{tabular}{|c|c|c|c|c|}
\hline \multirow[t]{2}{*}{ Sleep habits } & All & $\begin{array}{l}\text { Participants with EDS } \\
\text { (Epworth > 10) }\end{array}$ & $\begin{array}{l}\text { Participants without EDS } \\
\text { (Epworth } \leq 10)\end{array}$ & $\mathbf{p}$ \\
\hline & $n=501$ & $n=33$ & $n=468$ & \\
\hline Weekday (or workday) hours of sleep, mean (SD) & $6.8(1.1)$ & $6.5(1.2)$ & $6.9(1.0)$ & 0.145 \\
\hline Weekday (or workday) hours of sleep < 6h, n (\%) & $64(12.8)$ & $8(24.2)$ & $56(12.0)$ & 0.054 \\
\hline 24-hr weekday sleep (night + nap sleep), mean (SD) & $7.8(1.9)$ & $7.3(1.8)$ & $7.8(1.4)$ & 0.062 \\
\hline Weekend (or non-workday) hours of sleep, mean (SD) & $8.1(1.3)$ & $8.3(1.8)$ & $8.1(1.2)$ & 0.494 \\
\hline Regular bedtime, $\mathrm{n}(\%)$ & $362(72.3)$ & $19(57.4)$ & $343(73.3)$ & 0.055 \\
\hline Sleep latency (min), median (IQR) & $12.5(5.0-22.5)$ & $12.5(7.5-30.0)$ & $12.5(5.0-22.5)$ & 0.909 \\
\hline Napping, n (\%) & $127(25.3)$ & $17(50.4)$ & $110(23.5)$ & 0.001 \\
\hline Nap duration (min), median (IQR) [n = 127] & $37.5(30.0-60.0)$ & $35.5(30.0-45.0)$ & $40.0(30.0-60.0)$ & 0.157 \\
\hline \multicolumn{5}{|l|}{ Use of sleep medication, $\mathrm{n}(\%)$} \\
\hline Never (0 per month) & $411(82.0)$ & $26(78.8)$ & $385(82.3)$ & 0.541 \\
\hline Rarely (once per month) & $42(8.3)$ & $2(6.1)$ & $40(8.5)$ & \\
\hline Often (5-15 per month) & $9(1.8)$ & $1(3.0)$ & $8(1.7)$ & \\
\hline Almost always (16-30 per month) & $17(3.4)$ & $1(3.0)$ & $16(3.4)$ & \\
\hline \multicolumn{5}{|l|}{ Risk of sleep apnea (Berlin Questionnaire) } \\
\hline High risk of sleep apnea & $64(12.8)$ & $6(18.2)$ & $58(12.4)$ & 0.325 \\
\hline \multicolumn{5}{|l|}{ Traffic accidents } \\
\hline Work commute" traffic accidents, n (\%) & $54(10.8)$ & $5(15.2)$ & $49(10.5)$ & 0.385 \\
\hline
\end{tabular}

Abbreviations: ESD: excessive daytime sleepiness

The prevalence of "work commute" traffic accidents was $10.8 \%$ (95\% CI $8.0-13.7), 12.4 \%$ (95\% CI 5.9-18.8) in men and $10.4 \%$ (95\% CI: 7.6 a $13.7 \%)$ in women ( $\mathrm{p}=0.56)$. Results of the Berlin Questionnaire showed a high sleep apnea risk in 12.8\% (95\% CI 9.9$15.8)$ and were not significantly different in men and women $(16.2 \%$; 95\% CI 9.0-23.4 in men and 11.9\%; 95\% CI 8.4 - 14.8 in women, $\mathrm{p}=$ $0.20)$, or in patients with or without $\operatorname{EDS}(18.2 \%$ vs $12.4 \%, \mathrm{p}=0.325)$, or in those with day or night shifts (12.4 vs. $14.4 \%, \mathrm{p}=0.751)$.

Sleep habits of the study population, with or without EDS, are depicted in table 2. In the bivariate analysis, subjects with EDS showed a significantly higher sleep debt as compared with those without EDS (median $90 \mathrm{~min}$ vs. $60 \mathrm{~min}, \mathrm{p}=0.008$ ), and a higher percentage of them habitually napped $(50.4 \%$ vs. $23.5 \%, \mathrm{p}=0.001)$.
Characteristics of patients with day or night time shifts are displayed in table 3 .

Ninety-seven respondents worked night shifts and $91.8 \%$ of them were nurses $(52.6 \%)$ or nursing assistants $(36.1 \%)$.

There was a significantly higher sleep debt in night shift employees as compared with those working day shifts (median $94.5 \mathrm{~min}$ and $60 \mathrm{~min}$ respectively, $\mathrm{p}=0.027$ ), but no significant differences in the prevalence of EDS $(11.3 \%$ vs. $5.4 \%$ respectively, $\mathrm{p}=0.054)$ or "work commute" traffic accidents $(12.4 \%$ vs. $10 \%, \mathrm{p}=0.75)$ between both work schedules. Risk of sleep apnea as suggested by the Berlin Questionnaire was similar in night and day shift workers $(14.4 \%$ vs. $12.4 \%$ respectively, $\mathrm{p}=0.75)$. Women with night shifts showed higher abdominal circumference than daytime workers $(87.4(11.7) \mathrm{cm}$ vs. $82.2(10.5) \mathrm{cm}, \mathrm{p}=0.001$ and higher BMI, 
Table 3: Sleep habits, sleepiness symptoms, Berlin Questionnaire and "work commute" traffic accidents of 501 survey participants, according to work shift.

\begin{tabular}{|c|c|c|c|c|}
\hline \multirow[t]{2}{*}{ Sleep habits } & All & Day shift & Night shift & \\
\hline & $n=501$ & $n=404$ & $\mathrm{n}=97$ & $\mathbf{p}$ \\
\hline Weekday (or workday) hours of sleep, mean (SD) & $6.8(1.1)$ & $6.8(0.9)$ & $6.6(1.5)$ & 0.088 \\
\hline Weekday (or workday) hours of sleep < 7h, n (\%) & $220(43.9)$ & $167(41.3)$ & $53(54.6)$ & 0.039 \\
\hline Weekday (or workday) hours of sleep < 6h, n (\%) & $64(12.8)$ & $40(9.9)$ & $24(25.3)$ & $<0.001$ \\
\hline 24-hr weekday sleep (night + nap sleep), mean (SD) & $7.8(1.9)$ & $7.8(1.2)$ & $7.4(1.9)$ & 0.089 \\
\hline Weekend (or non-workday ) hours of sleep, mean (SD) & $8.1(1.3)$ & $8.1(1.2)$ & $8.3(1.4)$ & 0.310 \\
\hline Sleep debt (minutes), median (IQR) & $60.0(0.0-120.0)$ & $60.0(0.0-120.0)$ & 94.5(23.9-168.0) & 0.027 \\
\hline Regular bedtime, n (\%) & $362(72.3)$ & $306(75.7)$ & $56(57.7)$ & 0.001 \\
\hline Sleep latency (min), median (IQR) & $12.5(5.0-22.5)$ & $12.5(5.0-22.5)$ & $15.0(7.0-30.0)$ & 0.266 \\
\hline Nap, n (\%) & $127(25.3)$ & $78(19.3)$ & $49(50.5)$ & $<0.001$ \\
\hline Nap duration (min), median (IQR) [n = 127] & $37.5(30.0-60.0)$ & $37.0(25.0-60.0)$ & $45.0(30.0-90.0)$ & 0.018 \\
\hline \multicolumn{5}{|l|}{ Use of sleep medication, $\mathrm{n}(\%)$} \\
\hline Never (0 per month) & $411(82.0)$ & $338(83.3)$ & $73(76.8)$ & 0.229 \\
\hline Rarely (once per month) & $42(8.3)$ & $30(7.4)$ & $12(12.6)$ & \\
\hline Almost always (16-30 per month) & $17(3.4)$ & $13(3.2)$ & $4(4.2)$ & \\
\hline \multicolumn{5}{|l|}{ Sleepiness symptoms } \\
\hline Epworth Sleepiness Scale score > 10, n (\%) & $33(6.6)$ & $22(5.4)$ & $11(11.3)$ & 0.054 \\
\hline \multicolumn{5}{|l|}{ Risk of sleep apnea (Berlin Questionnaire) } \\
\hline High risk of sleep apnea & $64(12.8)$ & $50(12.4)$ & $14(14.4)$ & 0.751 \\
\hline \multicolumn{5}{|l|}{ Traffic accidents } \\
\hline "Work commute" traffic accidents, n (\%) & $54(10.8)$ & $42(10.4)$ & $12(12.4)$ & 0.751 \\
\hline
\end{tabular}

Abbreviations: IQR: interquartile range; SD: standard deviation

Table 4: Linear regression model of factors associated with BMI in all survey participants, stratified according to gender.

\begin{tabular}{|c|c|c|c|c|c|c|c|c|c|}
\hline & & All & & & Male & & & Female & \\
\hline & & $\mathrm{n}=\mathbf{5 0 1}$ & & & $n=105$ & & & $n=396$ & \\
\hline & Coefficient & $95 \% \mathrm{Cl}$ & p & Coefficient & $95 \% \mathrm{Cl}$ & p & Coefficient & $95 \% \mathrm{Cl}$ & p \\
\hline Night shift & 1.30 & $0.39-2.22$ & 0.005 & 0.55 & $-1.24-2.36$ & 0.542 & 1.56 & $0.53-2.58$ & 0.003 \\
\hline Sleep debt (hours) & 0.16 & $-0.07-0.39$ & 0.177 & 0.49 & $-0.03-1.02$ & 0.066 & 0.09 & $-0.16-0.35$ & 0.480 \\
\hline Age (years) & 0.12 & $0.09-1.15$ & 0.001 & 0.14 & $0.08-0.20$ & 0.001 & 0.13 & $0.09-0.16$ & 0.001 \\
\hline Active smoker & -0.37 & $-1.21-0.46$ & 0.38 & -0.78 & $-2.33-0.75$ & 0.31 & -0.18 & $-1.13-0.77$ & 0.710 \\
\hline ESS & -0.24 & $-1.17-1.65$ & 0.739 & -0.85 & $-3.37-1.66$ & 0.502 & -0.11 & $-1.74-1.51$ & 0.890 \\
\hline
\end{tabular}

Abbreviations: ESS: epworth sleepiness scale

Table 5: Logistic regression model of factors associated with daytime sleepiness in all survey participants, stratified according to gender.

\begin{tabular}{|c|c|c|c|c|c|c|c|c|c|}
\hline & & All & & & Male & & & Female & \\
\hline & & $n=501$ & & & $n=105$ & & & $n=396$ & \\
\hline & OR & $95 \% \mathrm{Cl}$ & $\mathbf{p}$ & OR & $95 \% \mathrm{Cl}$ & $\mathbf{p}$ & OR & $95 \% \mathrm{Cl}$ & $\mathrm{p}$ \\
\hline Night shift & 2.13 & $0.96-4.75$ & 0.063 & 0.94 & $0.10-9.06$ & 0.960 & 2.64 & $1.08-6.46$ & 0.033 \\
\hline Sleep debt (hours) & 1.25 & $0.99-1.57$ & 0.052 & 1.17 & $0.58-2.35$ & 0.656 & 1.27 & $0.99-1.62$ & 0.052 \\
\hline Age (years) & 1.01 & $0.97-1.04$ & 0.542 & 1.05 & $0.97-1.15$ & 0.182 & 1.00 & $0.96-1.04$ & 0.916 \\
\hline Active Smoking & 1.88 & $0.87-4.08$ & 0.106 & 2.87 & $0.52-16.05$ & 0.228 & 1.69 & $0.70-4.08$ & 0.243 \\
\hline BMI $\left(k g / m^{2}\right)$ & 1.09 & $0.88-1.21$ & 0.685 & 0.68 & $0.49-1.30$ & 0.356 & 1.09 & $0.91-1.31$ & 0.308 \\
\hline Abdominal circumference $(\mathrm{cm})$ & 0.97 & $0.92-1.03$ & 0.432 & 0.80 & $0.49-1.32$ & 0.395 & 0.95 & $0.89-1.02$ & 0.176 \\
\hline Berlin high risk sleep apnea & 1.56 & $0.87-4.08$ & 0.106 & 1.44 & $0.18-11.58$ & 0.730 & 1.36 & $0.39-4.63$ & 0.622 \\
\hline
\end{tabular}

Abbreviations: BMI: body mass index

(25.9 (4.4) $\mathrm{Kg} / \mathrm{m}^{2}$ vs. $24.1(4.2) \mathrm{Kg} / \mathrm{m}^{2} \mathrm{p}<0.001$ ), while no differences were observed in men. A linear regression analysis (Table 4) showed that age and a night shift were significant predictors of body mass index (coefficient $0.12, \mathrm{p}=0.001$ and $1.56, \mathrm{p}=0.003$, respectively) and of abdominal circumference (coefficient $0.29 \mathrm{p}=0.001$ and 3.95, $\mathrm{p}=0.003$ respectively), only in women.

Table 5 shows the results of the logistic regression to assess factors associated with EDS. Only women showed a significant association between EDS, a night shift (OR 2.64, $\mathrm{p}=0.034)$ and sleep debt (OR 1.29 for each hour, $\mathrm{p}=0.044)$, after adjusting for age, BMI, abdominal circumference, smoking and a high risk of sleep apnea.

After adjusting for ESS, age, gender, hours of sleep, daily alcohol intake, OSA high risk based on the Berlin Questionnaire, and a night shift schedule, "work commute" traffic accidents were significantly associated with age and "ever having dozed off while driving" (OR $1.037, \mathrm{p}=0.012$ and OR 2.675, $\mathrm{p}=0.04$, respectively), while ESS was not (OR 1.027, $\mathrm{p}=0.588)$.

\section{Discussion}

Our study of a population of health care employees in Spain has shown a prevalence of EDS of $6.6 \%$ and insufficient sleep time on work days in almost half the participants. EDS was associated with night shifts and with sleep debt only in women. "Work commute" traffic accidents were reported by $10.8 \%$ of responders. Age and having ever dozed off while driving were significantly associated with traffic accidents, whereas EDS and sleep time were not. Women with night shifts showed higher BMI and abdominal circumference compared to those with day shifts.

In population-based studies, the prevalence of severe daytime sleepiness, defined as "feeling excessive daytime sleepiness often or very often" or "as interfering with daily activities" has been reported by $4 \%$ to $35.8 \%$ of subjects, and is consistent with our finding [1,3-7]. We used ESS, as have many studies on this subject. Several studies focusing on populations of workers have reported EDS frequencies of ${ }^{\prime} 10.9 \%, 13.7 \%$ and $11.7 \%$, and sleep times of $7.20,7.05$ and 7.25 
hours, respectively $[5,6,21]$. In Spain, a population-based study of 2,148 subjects aged $30-70$ yrs., found EDS in $14 \%$ of men and $22 \%$ of women [22]. In the latter study, EDS was not associated with age or with OSA, and in both Spanish studies EDS was not identified by the ESS.

Our survey did not establish any relationship between gender and prevalence of EDS, which is consistent with most other study findings. Insufficient sleep is often associated with sleepiness, affecting about $8 \%$ of the general population [7]. Once insomnia or depression disorders have been excluded, the prevalence of insufficient sleep appears to decrease to $1 \%$ [23]. Several general population studies have shown a high rate of insufficient sleep time, affecting $23.1 \%$ of subjects with $31.3 \%$ of them referring daytime sleepiness [1,3-5,7]. In our survey, the mean sleep time was 6.8 hours on workdays and $43.9 \%$ slept less than 7 hours, with a mean sleep debt of 1 hour. The frequency of insufficient sleep in our population of health care employees is higher than has been previously described in a general population.

EDS in health care workers has been little investigated, and has mostly focused on night shift workers. One study of Japanese nurses described a similar rate of insufficient sleep, $28.1 \%$ of them sleeping less than 6 hours and $41.9 \%$ less than 7 hours 13 , with a $26.0 \%$ prevalence of EDS. In this study, EDS was significantly associated with occupational accidents over the last 12 months. Errors or accidents involving health care employees are an important issue as they impact the health status of their patients. A study focusing on physicians reported that $15.9 \%$ of them were habitually sleepy and that EDS was associated with working longer hours, habitual napping, and the feeling of not getting enough sleep [14]

We found that, only in women, night shifts (OR 2.47, $\mathrm{p}=0.048$ ) and sleep debt (OR 1.27 for each hour, $\mathrm{p}=0.049)$ were associated with EDS, after adjusting for age, BMI and a high risk of sleep apnea. This result might suggest that women are more affected by EDS after insufficient sleep time than men. In this regard, there is some evidence showing a higher prevalence of poor sleep in women as compared with men [23]. Besides, some studies have shown a higher risk of injury at work in women, as compared with men, especially in those referring less than 6 hours of sleep [24]. Possible interpretations of this difference between men and women could be that women may underestimate subjective time of sleep and that they have home duties that increase the feeling of tiredness or somnolence, more than men.

Although sleep debt likely accounts for a large part of EDS [1,3-7], notably few studies have investigated its diagnosis, ruling out other causes like OSA, insomnia, or depression. In a survey of 331 Australian workers, Johns $\mathrm{M}$ et al. showed an EDS prevalence of $10.9 \%$; EDS was attributed to insufficient sleep (almost 50\% slept less than 7 hours), insomnia (47.2\%) or to some evidence of sleep-disordered breathing (25\%) [21]. Our study did not address the diagnosis of insomnia or depression, although $3.4 \%$ of subjects referred using sleep medication almost always and $1.8 \%$ frequently. Sleep medication was not significantly associated with EDS in the logistic regression analysis. We investigated the probability of OSA using the Berlin Questionnaire and found a high risk of OSA in 12\% subjects but this factor reflected no association with EDS. Although EDS is the most common symptom of OSA, many OSA patients do not refer EDS. A study of a large Spanish cohort by Duran et al, found EDS in only $21 \%$ of men and $26 \%$ of women with OSA [22].

Subjects with night shifts showed a significant lower number of sleep hours during work days, as compared with daytime workers, and a higher sleep debt correlated weekends. A significantly higher number of subjects with night shifts napped habitually, also napping longer in duration compared to daytime workers. In our study, the prevalence of EDS was similar in night and daytime shift workers. This could be explained by the similar 24-hour weekday sleep in both shifts, as a significantly higher percentage of night shift workers napped habitually (50.5\%) as compared with daytime shift employees $(19.3 \%)$.

The prevalence of insomnia or excessive sleepiness (symptoms which define a "shift work sleep disorder") has been described in $32 \%$ and $26 \%$ of night and rotating shift workers, respectively [25]. A Spanish study of nurses found that for both men and women, shift work led to a reduction in the length of sleep (by 2 hours in those permanently on night shifts and by $30 \mathrm{~min}$ in those on a rotating night shift schedule) and that an alteration in the quality of sleep (difficulty in sleeping, intermittent sleep, early waking, etc.) was $10 \%$ more frequent [26].

On the other hand, it has been reported that night shift is associated to a higher calorie intake, higher BMI and higher morbidity of other causes [25]. A significant inverse association between sleep duration and obesity has also been described in a Spanish study showing that people who slept nine or more hours per day had less than half the risk of obesity than those sleeping only $6 \mathrm{~h}$ or less per day [27]. Another study demonstrated in a large sample of middle-aged women up to 65 years of age, that a habitual sleep time of less than 7 hours predicted increased future weight gain independent of baseline weight. Women sleeping 6 hours were 12 percent more likely to have a $15 \mathrm{~kg}$ weight gain, and women sleeping 5 hours or less were 32 percent more likely [28]. In line with these data, night shift workers in our survey showed higher BMI and abdominal circumference as compared with daytime workers, although only in women, and a linear regression analysis confirmed that both age and a night shift were significant predictors of BMI and abdominal circumference. Sleep schedules in night shift workers are a possible explanation for higher BMI in these patients, but the mechanism is uncertain, possibly related to lower physical activity although hormonal factors related to circadian rhythm variations could be involved. Since almost all night shift workers in our study were nurses or nursing assistants, we do not know whether this result might be generalizable to night shift employees of a different job classification.

The self-referred prevalence of work commute traffic accidents was $10.8 \%$ in our survey, without gender differences. According to data from the Spanish National Institute of Safety and Hygiene at Work, traffic accidents were much more common while commuting to or from work than during work periods $(72.5 \%$ vs. $27.5 \%)$ [17]. "Work commute accidents" constitute $13 \%$ of all work accidents. Interestingly, we found that subjects who reported ever having dozed off while driving, as compared with those who did not, referred fewer hours of sleep on work days, a higher frequency of EDS, and a higher auto-referral of traffic accidents. However, after adjusting for other factors, only age and ever having dozed off while driving were significantly associated with traffic accidents. This finding is consistent with previous reports in patients with OSA showing that sleepiness while driving is a risk factor for traffic accidents [29] and that driving while drowsy is associated with accidents in transportation operators [30].

\section{Limitations}

As self-administered questionnaires were used, a potential reporting bias must be factored into interpreting our results. EDS refers to sleep propensity during wakefulness and in situations of diminished attention and, although its measurement is complex, the ESS is a common instrument designed for evaluating the severity of EDS. However, only slight correlations have been found between subjective EDS assessed by ESS and objective measurements such as the Multiple Sleep Latency Tests [31]. We recognize that many factors, not considered in this study, affect sleep quality. However, in our EDS assessment, we factored in several important measures such as anthropometric variables, 24-hour sleep duration, daily alcohol and cigarette consumption, use of sleep medication as a surrogate for insomnia, and OSA risk. Although consecutive employees attending the annual medical check at the Occupational Risk Prevention Unit were recruited, these subjects were not compared with the overall employee population to assess representativeness. The proportion of men/women in our sample was nonetheless consistent with the proportion of men/women attending the Occupational Risk Unit medical screenings in our hospital. The size of the sample was calculated for the main outcome (prevalence of EDS) but the study 
may have lacked enough power to detect significant differences between groups (e.g. night shift workers vs. day shift workers, or women vs. men). Also, our results reflect mostly nurses and nursing assistants who constitute most of the night shift population at our study site. Another limitation of our study is that it is only representative of a single Spanish tertiary hospital and thus may not adequately represent the average health care employee population in Spain. Strengths of our study are that anthropometric data were objectively obtained at the time of a routine medical screening, the sample size was adequate for the assessment of the prevalence of EDS (the main outcome of the study), both day and night shifts were analyzed and finally, its anonymous nature enhances the probability of sincere answers.

\section{Conclusions}

In a Spanish health care employee population, EDS and insufficient sleep time are frequently reported, similar to what has been described that in previous studies in a general population in other countries. Insufficient sleep and a night shift are associated with EDS in women, and age and a night shift were significant predictors of overweight measurements also in women. Health services should alert workers about a higher risk of weight gain in women with night shifts and of "work commute" traffic accidents if experiencing sleepiness while driving.

\section{Acknowledgements}

The authors wish to thank Yvette Jusseaume for the English translation of the manuscript and Rosa Llòria for her help in the editorial assistance.

\section{Ethical Statement}

All procedures performed in studies involving human participants were in accordance with the ethical standards of the institutional and/or national research committee and with the 1964 Helsinki declaration and its later amendments or comparable ethical standards.

\section{References}

1. Bartlett DJ, Marshall NS, Williams A, Grunstein RR (2008) Sleep health New South Wales: Chronic sleep restriction and daytime sleepiness. Intern Med J 38: 24-31.

2. Dawson D, Reid K (1997) Fatigue, alcohol and performance impairment. Nature 388: 235

3. D'Alessandro R, Rinaldi R, Cristina E, Gamberini G LE (1995) Prevalence of excessive daytime sleepiness an open epidemiological problem. Sleep 18 389-391.

4. Hublin C, Kaprio J, Partinen M, Heikkilä K, Koskenvuo M (1996) Daytime sleepiness in an adult, Finnish population. J Intern Med 239: 417-423.

5. Lavie $P$ (1981) Sleep habits and sleep disturbances in industrial workers in Israel: main findings and some characteristics of workers complaining of excessive daytime sleepiness. Sleep 4: 147-158.

6. Ursin R, Baste V, Moen BE (2009) Sleep duration and sleep-related problems in different occupations in the Hordaland Health Study. Scand J Work Environ Health 35:193-202.

7. Ohayon MM (2008) From wakefulness to excessive sleepiness: what we know and still need to know. Sleep 12: 129-141.

8. Thorpy MJ (2012) Classification of Sleep Disorders. Neurotherapeutics 9: 687-701.
9. Philip P, Chaufton C, Orriols L, Lagarde E, Amoros E, et al. (2014) Complaints of poor sleep and risk of traffic accidents: A population-based case-contro study. PLoS One 9: e114102.

10. OhImann KK, O'Sullivan MI (2009) The costs of short sleep. AAOHN J 57 : 381-385.

11. Akerstedt T (2003) Shift work and disturbed sleep/wakefulness. Occup Med (Lond) 53: 89-94.

12. Gold DR, Rogacz S, Bock N, Tosteson TD, Baum TM, et al. (1992) Rotating shift work, sleep, and accidents related to sleepiness in hospital nurses. Am J Public Health 82: 1011-1014.

13. Suzuki K, Ohida T, Kaneita Y, Yokoyama E, Uchiyama M (2005) Daytime sleepiness, sleep habits and occupational accidents among hospital nurses. J Adv Nurs 52: 445-453.

14. Singh R, Undevia NS, Schuman C, Attarian H (2011) Excessive daytime sleepiness among attending physicians: A pilot survey study at an academic institution. Sleep Med 12: 808-810.

15. Wali SO, Krayem AB, Samman YS, Mirdad S, Alshimemeri AA, et al. (1999) Sleep disorders in Saudi health care workers. Ann Saudi Med 19: 406-409.

16. Luckhaupt SE, Tak S, Calvert GM (2010) The prevalence of short sleep duration by industry and occupation in the National Health Interview Survey. Sleep 33: 149-159.

17. (2012) Instituto Nacional de Seguridad e Higiene en el Trabajo. Accidentes laborales de tráfico.

18. Chiner E, Arriero JM, Signes-Costa J, Marco J, Fuentes I (1999) Validation of the Spanish version of the Epworth Sleepiness Scale in patients with a sleep apnea syndrome. Arch Bronconeumol 35: 422-427.

19. Netzer NC, Stoohs RA, Netzer CM, Clark K, Strohl KP (1999) Using the Berlin Questionnaire to identify patients at risk for the sleep apnea syndrome. Ann Intern Med 131: 485-91.

20. Institut Municipal d'Investigació Mèdica (IMIM) (2012) Sample size and power calculator GRANMO. Version 7.12.

21. Johns M, Hocking B (1997) Daytime sleepiness and sleep habits of Australian workers. Sleep 20: 844-849.

22. Durán J, Esnaola S, Rubio R, Iztueta Á (2001) Obstructive sleep apneahypopnea and related clinical features in a population-based sample of subjects aged 30 to $70 \mathrm{yr}$. Am J Respir Crit Care Med 163: 685-689.

23. Ohayon MM, Caulet M, Philip P, Guilleminault C, Priest RG (1997) How sleep and mental disorders are related to complaints of daytime sleepiness. Arch Intern Med 157: 2645-2652.

24. Nakata A, Ikeda T, Takahashi M, Haratani T, Hojou M, et al. (2006) The prevalence and correlates of occupational injuries in small-scale manufacturing enterprises. J Occup Health 48: 366-376.

25. Drake CL, Roehrs T, Richardson G, Walsh JK, Roth T (2004) Shift work sleep disorder: prevalence and consequences beyond that of symptomatic day workers. Sleep 27: 1453-1462.

26. Escribà V, Pérez-Hoyos S, Bolumar F (1992) Shiftwork: its impact on the length and quality of sleep among nurses of the Valencian region in Spain. Int Arch Occup Environ Health 64: 125-129.

27. Vioque J, Torres A, Quiles J (2000) Time spent watching television, sleep duration and obesity in adults living in Valencia, Spain. Int $\mathrm{J}$ Obes Relat Metab Disord 24: 1683-1688.

28. Patel SR, Malhotra A, White DP, Gottlieb DJ, Hu FB (2006) Association between reduced sleep and weight gain in women. Am J Epidemiol 164: 947-954.

29. Lloberes P, Levy G, Descals C, Sampol G, Roca A, et al. (2000) Self-reported sleepiness while driving as a risk factor for traffic accidents in patients with obstructive sleep apnoea syndrome and in non-apnoeic snorers. Respir Med 94: 971-976.

30. Johnson KD, Patel SR, Baur DM, Edens E, Sherry P, et al. (2014) Association of Sleep Habits With Accidents and Near Misses in United States Transportation Operators. J Occup Environ Med 56: 510-515.

31. Kim H, Young T (2005) Subjective daytime sleepiness: dimensions and correlates in the general population. Sleep 28: 625-634. 